\title{
Seasonal discrepancies in denitrification measured by isotope pairing and $\mathrm{N}_{2}$ :Ar techniques
}

\author{
Angus J. P. Ferguson ${ }^{1,2}$, Bradley D. Eyre ${ }^{1, *}$ \\ ${ }^{1}$ Centre for Coastal Biogeochemistry, Southern Cross University, PO Box 157, Lismore, New South Wales 2480, Australia \\ ${ }^{2}$ Present address: Aquatic Biogeochemical and Ecological Research, PO Box 409, Brunswick Heads, \\ New South Wales 2483, Australia
}

\begin{abstract}
Isotope pairing (IP) and $\mathrm{N}_{2}$ :Ar techniques for measuring sediment denitrification were compared in muddy sediments in a shallow sub-tropical embayment. At a concentration of $100 \mu \mathrm{M}$ ${ }^{15} \mathrm{NO}_{3}{ }^{-}$(our experimental conditions), IP greatly underestimated denitrification, compared to $\mathrm{N}_{2}: \mathrm{Ar}$, in low-respiration sediments subject to bioturbation, where denitrification produced via coupled nitrification-denitrification $\left(D_{\mathrm{n}}\right)$ dominates overall denitrification. Consistent with this underestimation was the higher $\mathrm{N}_{2}$ flux measured using $\mathrm{N}_{2}$ :Ar ratios, accounting for more of the stochimetrically predicted $\mathrm{N}$ mineralisation. We suggest that this underestimation is primarily due to non-homogenous mixing of the added ${ }^{15} \mathrm{NO}_{3}{ }^{-}$with the endogenous ${ }^{14} \mathrm{NO}_{3}{ }^{-}$in the sediment, associated with differentials in the rate of diffusion of ${ }^{15} \mathrm{NO}_{3}{ }^{-}$across mucus linings in burrow structures versus rates of ${ }^{14} \mathrm{NO}_{3}{ }^{-}$supply from nitrifiers in the burrow walls. Strong support for this hypothesis was provided by the relationship between the methods discrepancy and polychaete biomass $\left(\mathrm{r}^{2}=0.99 ; \mathrm{p}=0.001\right)$, and the almost complete removal of the methods discrepancy when the upper heterogenous sediment layer that contained the burrow structures was experimentally removed. Due to a significant increase in potential denitrification sites in association with burrow structures, this effect can potentially cause a large underestimation of denitrification (up to $85 \%$ ) using the IP technique. Our data show no benefit in longer preincubation times, suggesting that this effect may represent a fundamental limitation of the IP method in the sediments of oligotrophic (low carbon loading) systems. As such, the $\mathrm{N}_{2}$ :Ar flux technique represents a more realistic estimation of net denitrification in sediments with low organic carbon contents and low respiration rates and significant bioturbation. Most importantly, the present study also demonstrated that methodological comparisons need to be made over a range of environmental conditions.
\end{abstract}

KEY WORDS: Methods comparison $\cdot$ Denitrification $\cdot \mathrm{N}_{2}$ :Ar $\cdot$ Isotope pairing $\cdot$ Sediments $\cdot$ Benthic microalgae $\cdot$ Macrofauna $\cdot$ Bioturbation

\section{INTRODUCTION}

Denitrification has been recognised for some time as an important process in maintaining the balance between fixed and atmospheric $\mathrm{N}_{2}$ in aquatic ecosystems (Seitzinger 1988). Early investigations found discrepancies in coastal nitrogen budgets and explained the large amounts of 'missing nitrogen' as most likely being removed via denitrification (Nixon 1981, 1987). Likewise, many early benthic flux studies analysed the stoichiometric relationship between benthic respiration and dissolved inorganic nitrogen (DIN) flux, attributing the shortfall in DIN remineralisation (as- suming the breakdown of Redfield algae) to denitrification (Banta et al. 1994, Berelson et al. 1998). The implied importance of denitrification in N-limited coastal systems prompted a need to directly measure the process in order to better understand its significance and controlling factors.

Denitrification is controlled by complex interactions between organic carbon (OC) supply, water column nitrate, other microbial processes such as nitrification and benthic microalgae (BMA) production, bioturbation and sediment properties (Christensen et al. 1990, Risgaard-Petersen et al. 1994, Rysgaard et al. 1994). Early techniques developed to measure benthic de- 
nitrification were either cumbersome or involved too many artefacts to be useful. For example, the direct $\mathrm{N}_{2}$ flux method involved long pre-incubation times, the complete removal of background $\mathrm{N}_{2}$ concentrations and the maintenance of anoxic conditions (Seitzinger 1987). Another widely used technique was the acetylene-block method, which inhibited nitrification and was measured on sediment slurries (Sørensen 1978). The artefacts associated with these methods were likely to dramatically alter benthic processes from in situ and provide unreliable estimates of denitrification. Hence, there was a need to develop methods that could measure denitrification in undisturbed sediments, thereby preserving the interactions between controlling factors as much as possible and providing a more realistic estimate.

The isotope pairing (IP) technique (Nielsen 1992) and the direct $\mathrm{N}_{2}$ flux measured using $\mathrm{N}_{2}$ :Ar ratios (Kana et al. 1994) on a membrane inlet mass spectrometer (MIMS) are 2 techniques that are capable of providing denitrification estimates in relatively undisturbed sediments. As a result they have become the most widespread techniques used in current aquatic research (e.g. Risgaard-Petersen et al. 1994, Rysgaard et al. 1996, Kana et al. 1998, Sundback \& Miles 2000, Eyre \& Ferguson 2002, 2005). While both techniques are used as an estimate of benthic denitrification, they measure distinctly different things. IP measures the depth-integrated denitrification activity over the timescale of the incubation; however, this estimate is heavily dependent on non-violation of the 4 assumptions for the method (Nielsen 1992, Eyre et al. 2002). Direct $\mathrm{N}_{2}$ flux (measured by $\mathrm{N}_{2}$ :Ar ratios) represents the net benthic flux of $\mathrm{N}_{2}$ resulting from a combination of processes that produce $\mathrm{N}_{2}$, such as denitrification and anammox, and processes that consume $\mathrm{N}_{2}$ such as $\mathrm{N}$-fixation. As such, the $\mathrm{N}_{2}$ :Ar estimate represents a 'net denitrification' rate and the flux is the net result of processes operating over a longer time frame than the incubation (i.e. hours to days), although the technique can respond to rapid rate changes (e.g. Kana et al. 1998).

Cook et al. (2006) compared $\mathrm{N}_{2}: \mathrm{Ar}$ and IP techniques in sandy sediments and found there were problems with the IP technique due to non-homogeneous mixing of the tracer if a $24 \mathrm{~h}$ pre-incubation period after addition of the tracer was not maintained. In contrast, the $\mathrm{N}_{2}$ :Ar technique gave a better estimate of the denitrification in sandy sediments as long as steady-state conditions were maintained (Cook et al. 2006). The only study comparing the $\mathrm{N}_{2}$ :Ar and IP techniques in muddy sediments has shown close agreement (within $25 \%$ ) in temperate coastal sediments at higher denitrification rates (99 to $124 \mu \mathrm{mol} \mathrm{N} \mathrm{m}{ }^{-2} \mathrm{~h}^{-1}$ ), and provides evidence of the potential influence of $\mathrm{N}$-fixation on direct $\mathrm{N}_{2}$ flux (Eyre et al. 2002). However, that study only compared dark rates and was limited in temporal and spatial replication; therefore, the effects of seasonal variation in factors such as benthic respiration rates, infauna abundance, ambient nitrogen concentrations, light climate and benthic microalgal production on the agreement between methods are unknown. As denitrification rates between different ecosystems and regions must be compared in order to further our understanding of global denitrification, there is a need to 'calibrate' estimates given by the 2 dominant current methods across a wide range of environmental gradients. This study presents the first comprehensive comparison of the IP and $\mathrm{N}_{2}$ :Ar techniques over a full year in muddy sediments of a shallow, oligotrophic, subtropical coastal embayment.

\section{MATERIALS AND METHODS}

Benthic incubations. The study site was situated in Deception Bay, part of western Moreton Bay, a shallow (mean depth $7 \mathrm{~m}$ ), sub-tropical embayment adjacent to Brisbane city on the east coast of Australia. Three main sites were located $500 \mathrm{~m}$ apart in a north-eastern transect away from the Caboolture River mouth. Each main site consisted of 2 sub-sites located $50 \mathrm{~m}$ apart along the north-eastern transect ( 6 sub-sites in total). All sites were in water approximately $4 \mathrm{~m}$ deep (mean high tide).

Samples were collected 6 times over a 13 mo period. On each sample occasion, 6 undisturbed replicate sediment cores (acrylic $95 \mathrm{~mm}$ inner diameter; $30 \mathrm{~cm}$ of water; $20 \mathrm{~cm}$ of sediment) were collected by divers from the 6 sites (36 cores in total) within Deception Bay, between approximately midday and 15:00 h. A $150 \mathrm{l} \mathrm{sam-}$ ple of water was also collected from the site. Incident radiation (downwelling) was measured at the top and bottom of the water column at the sample site using a Li-Cor 250 light meter. Cores were transported at in situ temperature and light to the laboratory within $2 \mathrm{~h}$ of collection, where they were placed uncapped into several incubators with $150 \mathrm{l}$ of recirculated and aerated site water at the collection temperature, $\pm 1^{\circ} \mathrm{C}$ ). The in situ diel light/dark climate $( \pm 5 \%)$ was maintained throughout the incubation, and irradiance (Phillips Son-T 400 AGRO PAR Light) at the sediment core surface during the light period was set at the daily mean irradiance at the sediment surface at the site of collection $\left(<10 \mu \mathrm{mol} \mathrm{m}{ }^{-2} \mathrm{~s}^{-1}\right)$. Cores were equipped with self-stirrers set $10 \mathrm{~cm}$ above the sediment surface, with stirring rates just below that which causes resuspension. A $24 \mathrm{~h}$ equilibration period was imposed, and benthic flux incubations started at approximately $2 \mathrm{~h}$ after sunset the following evening. Cores were capped, and dissolved 
oxygen concentrations $\left( \pm 0.01 \mathrm{mg} \mathrm{l}^{-1}\right)$ and $\mathrm{pH}( \pm 0.001$ $\mathrm{pH}$ units) were measured electro-chemically. Alkalinity, nutrient and $\mathrm{N}_{2}$ samples were collected every $4 \mathrm{~h}$ over a dark/light period. To avoid bubble formation during the light cycle, which may result in an underestimate of benthic production (Dalsgaard et al. 2000) and will interfere with the $\mathrm{N}_{2}$ :Ar concentrations (Eyre et al. 2002), the partial pressure and concentration of $\mathrm{O}_{2}$ was lowered by always running the dark incubation prior to the light incubation (Eyre \& Ferguson 2002). Dissolved oxygen typically only decreased about $20 \%$ over the course of the dark incubation. Nutrient and alkalinity samples were withdrawn with a plastic syringe and transferred to $10 \mathrm{ml}$ acid-rinsed and sample-rinsed polyethylene vials. As a sample was withdrawn, an equal amount was replaced from a gravity-fed reservoir of estuary water. To minimise the introduction of bubbles, $\mathrm{N}_{2}$ samples were collected in triplicate by allowing water to flow, driven by the reservoir head, directly into $7 \mathrm{ml}$ gas-tight glass vials with glass stoppers filled to overflowing. The replacement water was withdrawn from a sealed collapsible reservoir bag, also equilibrated at in situ light $( \pm 5.0 \%)$ and temperature $\left( \pm 1^{\circ} \mathrm{C}\right)$ conditions, to maintain constant Ar concentrations (Eyre et al. 2002). All nutrient samples were immediately frozen at $-20^{\circ} \mathrm{C}$. $\mathrm{N}_{2}$ samples were poisoned with $20 \mu \mathrm{l}$ of $5 \% \mathrm{HgCl}_{2}$ and stored submerged at ambient temperature. Alkalinity samples were kept cold at $4^{\circ} \mathrm{C}$. The $\mathrm{O}_{2}, \mathrm{TCO}_{2}$, alkalinity and nutrient data will be presented in full elsewhere.

Following the completion of the $\mathrm{N}_{2}$ :Ar light period, cores were uncapped and allowed to freely exchange with the incubator water for $3 \mathrm{~h}$ (Fig. 1). IP was then undertaken as detailed in Eyre et al. (2002) by adding ${ }^{15} \mathrm{NO}_{3}$ to the incubator water to a concentration of $100 \mu \mathrm{M}$. We chose to use the same approach as Eyre et al. (2002), whereby IP was carried out on the same cores as $\mathrm{N}_{2}: \mathrm{Ar}$, because the large number of sites and replicates meant that we were unable to incubate additional cores for IP. A period of $3 \mathrm{~h}$ (based on $\mathrm{O}_{2}$ microprofiles measured using a $20 \mu \mathrm{m}$ UNISENSE microsensor; Dalsgaard et al. 2000) was allowed for the downward mixing of ${ }^{15} \mathrm{NO}_{3}$, before cores were capped and the first cores $\left(T_{0}\right)$ from each site sacrificed. $\mathrm{O}_{2}$ penetration depth during the study varied between 2.5 and $4 \mathrm{~mm}$ during the light. One core from each site was sacrificed every $4 \mathrm{~h}\left(T_{1-5}\right)$ during the following dark/light period (Fig. 1). A Plexiglas rod was used to carefully mix the sediment and water, and the resultant slurry was sampled by syringe. The slurry was transferred to $7 \mathrm{ml}$ gas-tight glass vials with glass stoppers filled to overflowing and poisoned with $20 \mu \mathrm{l}$ of $5 \% \mathrm{HgCl}_{2}$.

$\mathrm{N}_{2}$ : Ar and ${ }^{14} \mathrm{~N}^{15} \mathrm{~N}$ and ${ }^{15} \mathrm{~N}^{15} \mathrm{~N}$ samples were analysed on a MIMS with a copper reduction furnace to remove oxygen as detailed in Eyre et al. (2002). Direct $\mathrm{N}_{2}$ flux rates for dark, light and net periods were calculated from the concentration series (Eyre \& Ferguson 2005), while denitrification rates estimated from IP were calculated following the methods outlined in Nielsen (1992).

At the end of the incubation, a fraction of the top $5 \mathrm{~mm}$ of each sediment core was sampled and stored at $-20^{\circ} \mathrm{C}$, until analysis for OC and nitrogen on a LECO CNS analyzer (Ferguson et al. 2003). For the last 5 of the 6 sample periods, the remaining sediment core was transferred to a calico bag and stored in $70 \%$ ethanol until sieving through a $1 \mathrm{~mm}$ mesh size sieve for macrofauna. Macrofauna were identified to the lowest taxonomic level possible (typically species), and the wet weight of samples was measured to $0.01 \mathrm{~g}$ after blot-drying on tissue paper. Macrofauna biomass throughout the study was dominated by bristle crabs Pilumnus sp. (63\%) followed by bivalves $(26 \%)$, polychaetes $(6 \%)$ and echinoderms (Ophiactidae; 5\%). Despite the low contribution of polychaetes to overall macrofauna biomass, polychaetes were consistently the dominant group with regards to density ( 22 to $86 \%$ of total macrofauna density, mean $=42 \%$ ). Only the polychaete biomass is presented here, with the full macrofauna data set presented elsewhere. All statistical analysis was undertaken using SPSS v. 11.5.

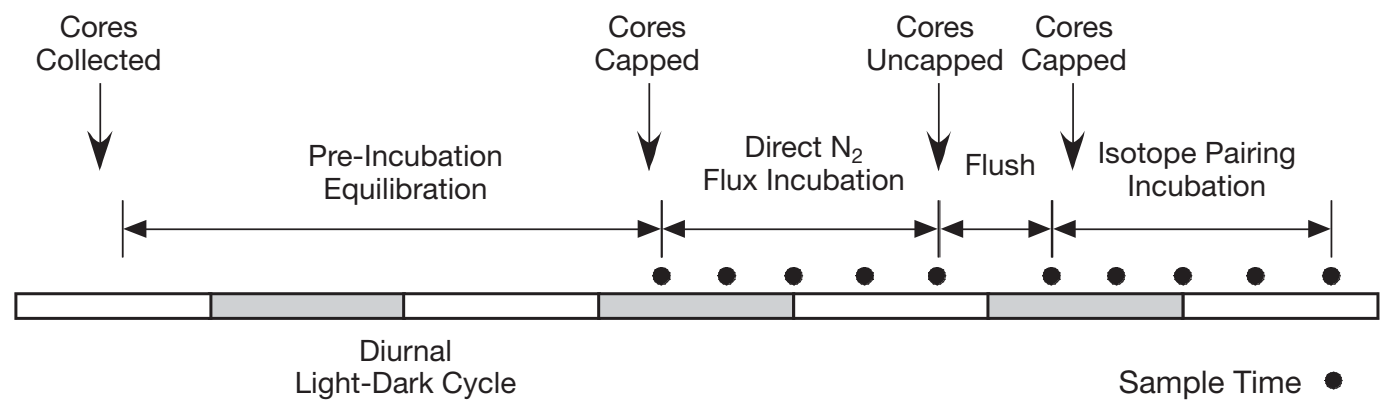

Fig. 1. Incubation strategy employed during the study, showing the timing of pre-incubation period, $\mathrm{N}_{2}:$ Ar flux incubations and isotope pairing incubations 
The present study was carried out as part of a larger study investigating the effects of trawling on denitrification. Briefly, the 6 sample sites $(20 \mathrm{~m} \times 20 \mathrm{~m})$ described above comprised paired (treatment/control) sub-sites (a/b) within 3 main replicate sites $(1,2,3)$ (separated by $500 \mathrm{~m}$ ). During mid-summer, early autumn and late autumn, 1 sub-site (treatment) within each main site was trawled intensively immediately after the pre-trawl samples were taken and then resampled within $2 \mathrm{~h}$. All the data in this study are pretrawl, except where specifically referred to as posttrawl data.
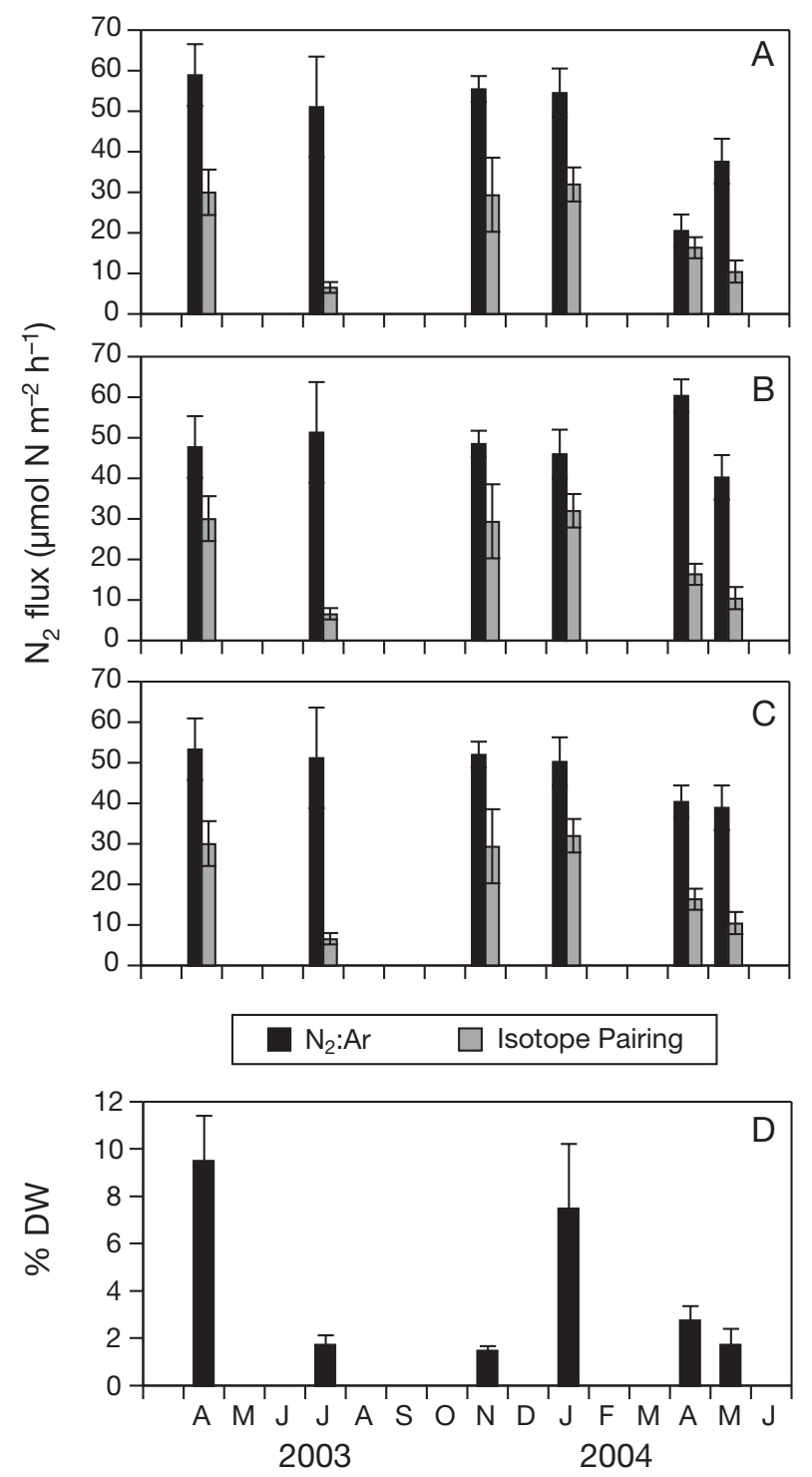

Fig. 2. Mean $( \pm \mathrm{SE}) \mathrm{N}_{2}$ flux measured using $\mathrm{N}_{2}$ :Ar $(\mathrm{n}=36$ replicates; sites pooled) and mean $( \pm \mathrm{SE})$ isotope pairing rate ( $\mathrm{n}=6$ replicates; i.e. 6 cores per isotope pairing rate; 1 per time period) for each sample run during: (A) the dark, (B) the light and (C) the net diel period. (D) Estimated percentage of direct denitrification $D_{\mathrm{w}}$ (relative to total $D_{\mathrm{w}}+D_{\mathrm{n}}$ ) over the net diel period

\section{RESULTS}

Direct $\mathrm{N}_{2}$ fluxes measured using $\mathrm{N}_{2}$ :Ar ratios (MIMS) and denitrification rates measured using IP during the light and dark for each sample time are shown in Fig. 2. $\mathrm{N}_{2}$ flux significantly exceeded $(\mathrm{p}<0.05)$ the IP rate during all runs, ranging between 1.6 and 9.4 times greater. $\mathrm{N}_{2}$ :Ar rates showed significant $(\mathrm{p}<0.05)$ light/dark variations at some sites, but overall light/dark variations were not significant due to significant light $\times$ site and light $\times$ sample time interactions (Fig. 2). The IP rates showed no distinct light/dark variations, as none of the time series were significantly non-linear (Fig. 2; run test; Motulsky \& Christopoulos 2003). Direct denitrification of water column nitrate $\left(D_{\mathrm{w}}\right)$ was relatively unimportant during this study ( $<10 \%$; Fig. 2) with most of the denitrification produced via coupled nitrification-denitrification $\left(D_{\mathrm{n}}\right)$. The magnitude of the difference between the 2 methods ( $\mathrm{N}_{2}$ :Ar vs. IP) was strongly related to polychaete biomass ( $\mathrm{r}^{2}=0.99$; $\mathrm{p}<0.001$; Fig. 3$)$.

Average benthic respiration rates were always $<1200 \mu \mathrm{mol} \mathrm{O} \mathrm{O}^{-2} \mathrm{~h}^{-1}$ (Fig. 4). A comparison between benthic respiration and inorganic $\mathrm{N}$ mineralisation $\left(\mathrm{DIN}+\mathrm{N}_{2}\right.$ ) was made using the 2 estimates of denitrification (Fig. 4). The higher $\mathrm{N}_{2}$ flux measured using $\mathrm{N}_{2}$ :Ar ratios accounted for more of the predicted $\mathrm{N}$ mineralisation (assuming the breakdown of Redfield algae, $C: N=6.6: 1$, with the remineralised $C: N$ flux approaching Redfield in mid-summer and late autumn,

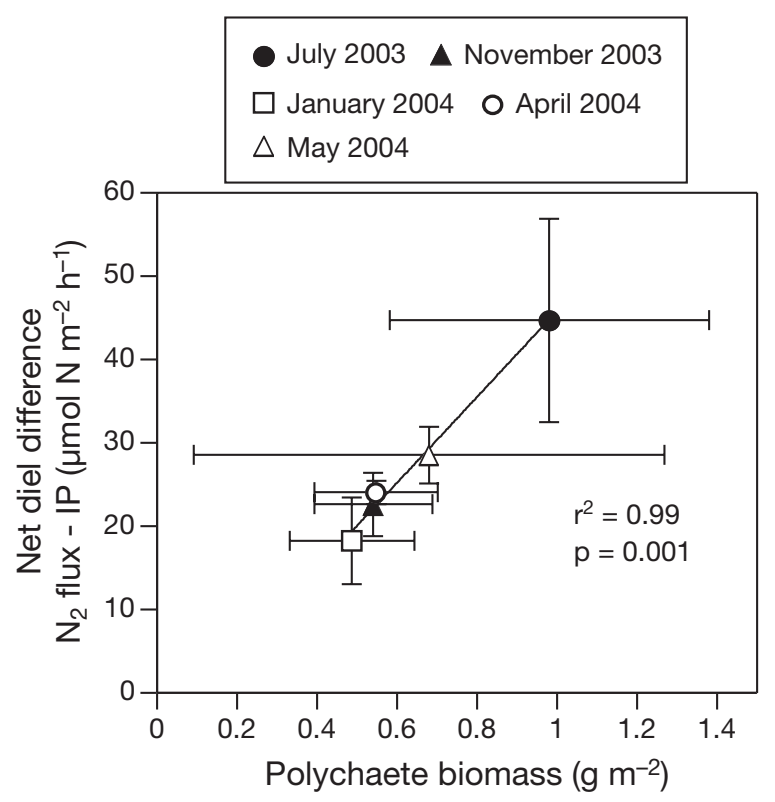

Fig. 3. Difference $\left(\mu \mathrm{mol} \mathrm{N} \mathrm{m} \mathrm{N}^{-2} \mathrm{~h}^{-1}\right.$ ) between the $\mathrm{N}_{2}$ :Ar and isotope pairing techniques over the net diel period (sites pooled) for each sample time as a function of polychaete biomass (mean $\pm \mathrm{SE}$ ). Note: macrofauna biomass was not collected on the first sample run and hence $n=5$ 


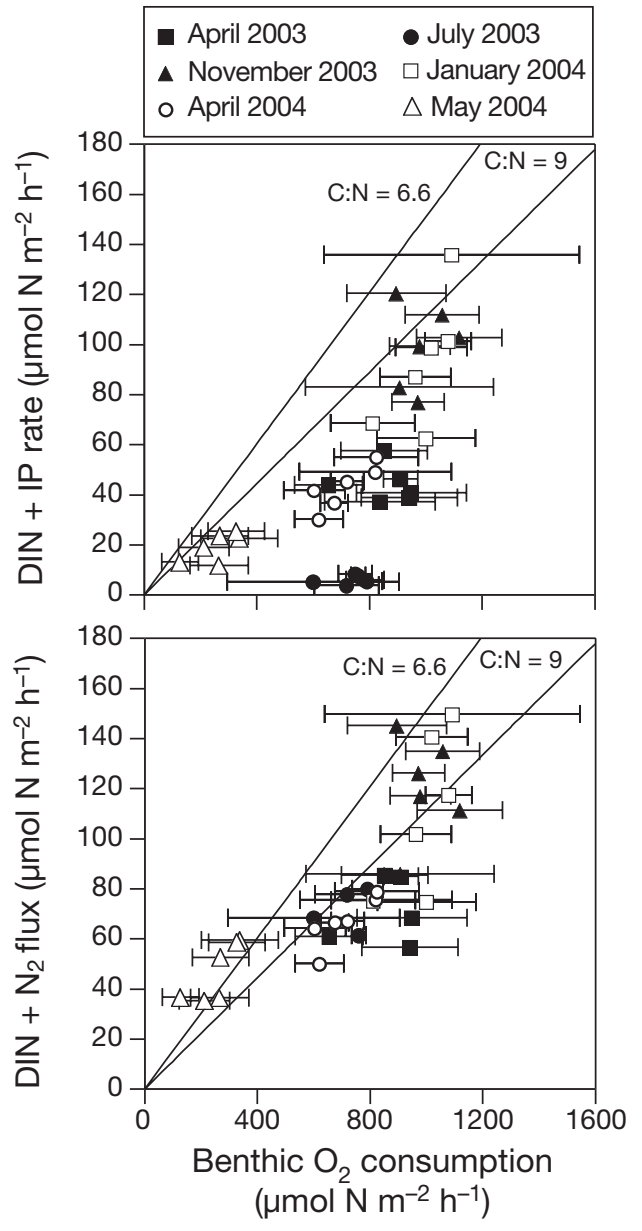

Fig. 4. Relationship between organic matter mineralisation (estimated as mean \pm SE benthic $\mathrm{O}_{2}$ consumption) and total mean dissolved inorganic nitrogen (DIN) regeneration plus denitrification estimated using: (A) the isotope pairing (IP) rate and (B) the direct $N_{2}$ flux using $N_{2}$ :Ar ratios, for each sample time $(\mathrm{n}=6$ replicates). Redfield $\mathrm{C}: \mathrm{N}=6.6: 1$; measured sediment $\mathrm{C}: \mathrm{N}=9$ but predominantly plotting closer to the sediment $\mathrm{C}: \mathrm{N}$ of around 9 (Fig. 4). Denitrification rates measured by the IP method were up to $85 \%$ less than rates measured by the $\mathrm{N}_{2}$ :Ar technique (Table 1).

Trawling caused resuspension of the top $10 \mathrm{~mm}$ of the sediment surface (visual observation), with deposition of resuspended material and fresh phytodetritus proceeding immediately post-trawl. Visual inspection of pre- and post-trawl sediments revealed a complete loss of the heterogenous structure imparted by burrow structures due to trawling, with this replaced by a fine blanket of freshly deposited material. $\mathrm{N}_{2}$ :Ar fluxes in the post-trawled sediments agreed more closely with IP measurements made at the same site on the day preceding trawling (Fig. 5).

\section{DISCUSSION}

Comparisons of the direct $\mathrm{N}_{2}$ flux and IP methods have shown both poor (within 100\%; Van Luijn et al. 1996) and good (within 1\%; Risgaard-Petersen et al. 1998) agreement. The only previous comparison of the $\mathrm{N}_{2}$ :Ar flux and IP method in muddy sediments has also shown that these methods can agree to within $25 \%$ (Eyre et al. 2002). However, these previous comparisons showing good agreement between the $\mathrm{N}_{2}$ flux and IP and $\mathrm{N}_{2}$ :Ar flux and IP methods were carried out in temperate systems with higher OC loadings and higher denitrification rates (i.e. $>90 \mu \mathrm{mol} \mathrm{N} \mathrm{m}^{-2} \mathrm{~h}^{-1}$ ) than those existing during the present study (net $<55 \mu \mathrm{mol} \mathrm{N} \mathrm{m}^{-2} \mathrm{~h}^{-1}$ ). In addition, the IP technique has been primarily used in temperate systems with high water column nitrate concentrations, resulting in a dominance of $D_{\mathrm{w}}$. This study shows that, in our oligotrophic system where OC loading, respiration rates and water column nitrate concentrations are all low and $D_{\mathrm{n}}$ dominates, either the $\mathrm{N}_{2}$ :Ar method is overestimating denitrification rates and/or the IP technique is underestimating denitrification rates.

\section{Experimental design}

For any methods comparison it is important that there is no systematic bias in the experimental design. We chose to run the IP on the same cores used for the $\mathrm{N}_{2}$ :Ar method, as this approach has been used previously (see Eyre et al. 2002) and it would have been logistically impossible to incubate additional cores for IP due to the large number of sites and replicates. IP was always run 


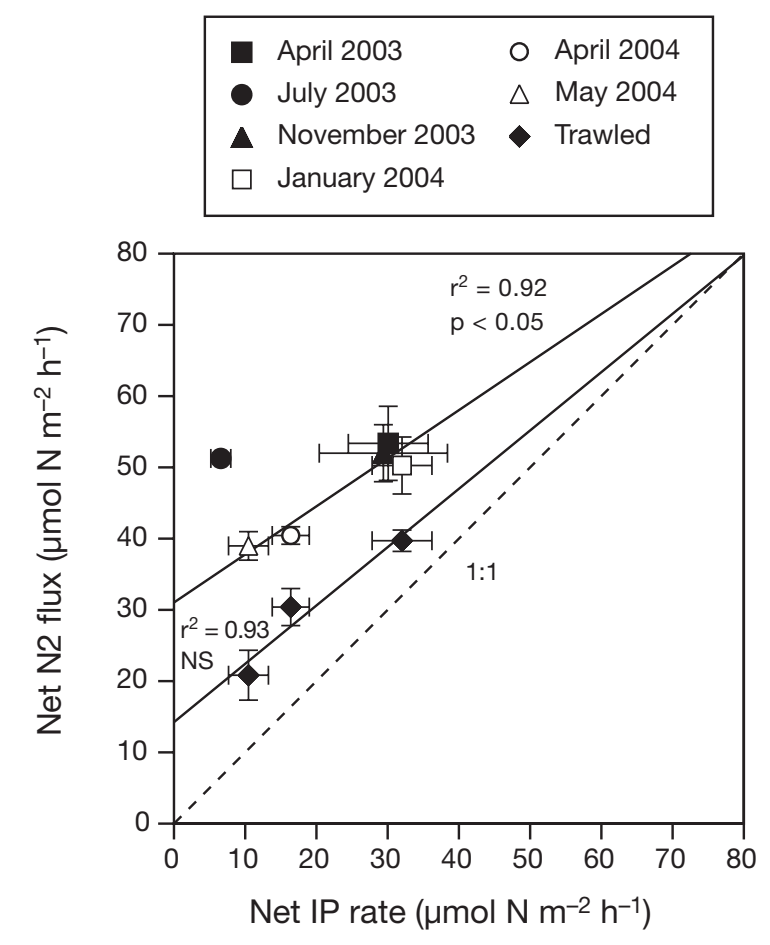

Fig. 5. Comparison of the 2 estimates of denitrification (mean $\pm \mathrm{SE}$ ) showing the decrease in the discrepancy as overall rates increased. Extrapolation of these relationships (July 2003 excluded) predicts convergence of estimates at a denitrification rate $>80 \mu \mathrm{mol} \mathrm{N} \mathrm{m}{ }^{-2} \mathrm{~h}^{-1}$. If July 2003 is included, the curve fit is poorer $\left(\mathrm{r}^{2}=0.29\right.$; not significant) and the pre-trawling convergence occurs at $\sim 60 \mu \mathrm{mol} \mathrm{N} \mathrm{m}{ }^{-2} \mathrm{~h}^{-1}$. Pre-trawled samples ( $\mathrm{n}=36$ replicates; sites pooled) and post-trawled samples ( $\bullet$, $\mathrm{n}=18$ replicates; sites pooled) show the virtual removal of the discrepancy between $\mathrm{N}_{2}$ :Ar fluxes in the post-trawled sediments and IP measurements made at the same site on the day preceding trawling, due to the resuspension of the surface sediments and breakdown of the heterogenous structure imparted by polychaete burrows and other bioturbators

after the $\mathrm{N}_{2}$ :Ar incubations because it is a destructive technique. It is possible that the longer containment before the IP experiments were run may have biased the findings. Possible changes during long containments include denudation of BMA biomass and labile OC by infauna and changed redox conditions. However, there are a number of reasons why we do not believe that this influenced our results. In our experimental design the cores were flushed between incubations and oxygen was not allowed to drop $>20 \%$ during an incubation, suggesting redox conditions in the sediment should not have changed. We saw no obvious signs of changes in BMA biomass (i.e. change in surface colour) and infauna activity (i.e. no dead infauna), something that we closely observed. Most importantly, if these changes did occur, and they influenced the measured rates, they would have occurred gradually and we would have seen a systematic decrease or increase in IP or $\mathrm{N}_{2}$ :Ar rates over the course of the $24 \mathrm{~h}$ incubations; none of the IP or $\mathrm{N}_{2}$ :Ar time series were significantly non-linear (except for light/dark changes in $\mathrm{N}_{2}$ :Ar), indicating that there was no systematic bias in our experiments.

\section{Does the $\mathrm{N}_{2}$ :Ar method underestimate denitrification rates?}

There are a number of artefacts that can occur when using the $\mathrm{N}_{2}$ :Ar method to measure denitrification rates, including oxygen interference during analysis, $\mathrm{O}_{2}$ bubble formation in the cores due to highly productive sediments, bubble formation in the samples if warmed after collection and loss of $\mathrm{N}_{2}$ via $\mathrm{N}$-fixation (Eyre et al. 2002). Before analysis of $\mathrm{N}_{2}$ :Ar, oxygen was removed using an in-line copper reduction furnace (Eyre et al. 2002), so oxygen interference was not a problem during analysis. Oxygen bubbles pose a problem for the $\mathrm{N}_{2}$ :Ar technique because of the higher solubility of $\mathrm{N}_{2}$ compared to $\mathrm{Ar}$ in the bubbles (Eyre et al. 2002). There were no visible bubbles in any of our cores or samples, and, although the production of non-visible bubbles cannot be ruled out, bubbles result in an underestimation of denitrification rates. Similarly, if significant $\mathrm{N}$-fixation occurred, denitrification rates measured using the $\mathrm{N}_{2}$ :Ar technique would also be underestimated. Most importantly, the higher $\mathrm{N}_{2}$ flux measured using $\mathrm{N}_{2}$ :Ar ratios, accounting for more of the stoichiometrically predicted $\mathrm{N}$ mineralisation flux (Fig. 4), suggests that IP was underestimating the rate of denitrification and that the $\mathrm{N}_{2}$ :Ar rates were not overestimated. It is unlikely that the stoichiometrically predicted $\mathrm{N}$ mineralisation flux using $\mathrm{N}_{2}$ :Ar ratios fell close to the Redfield or the sediment $\mathrm{C}: \mathrm{N}$ ratio, and that the stoichiometrically predicted $\mathrm{N}$ mineralisation flux using IP always had a lower ratio, by coincidence. In addition, the relationships between the IP rate and $\mathrm{N}_{2}$ flux (Fig. 5) suggest convergence of the method estimates at a net denitrification rate of $>80 \mu \mathrm{mol} \mathrm{N} \mathrm{m} \mathrm{N}^{-2} \mathrm{~h}^{-1}$. It is above this rate where the methods have previously been shown to compare well (see Eyre et al. 2002). Hence, the potential underestimation of denitrification by IP is particularly relevant in oligotrophic systems where OC loading, respiration rates and water column nitrate concentrations are all low and $D_{\mathrm{n}}$ dominates.

\section{Does the IP method underestimate denitrification rates?}

Potential artefacts in the IP technique may arise due to violation of one or more of the 4 assumptions critical to the method: (1) a stable $\mathrm{NO}_{3}{ }^{-}$concentration gradient 
forms a short time after the tracer is added, (2) the rate of $D_{\mathrm{n}}$ is unchanged by the ${ }^{15} \mathrm{NO}_{3}{ }^{-}$addition, (3) that interference by anammox ( $\mathrm{N}_{2}$ production from the oxidation of $\mathrm{NH}_{4}^{+}$by $\mathrm{NO}_{3}^{-}$) is negligible and (4) that the added ${ }^{15} \mathrm{NO}_{3}{ }^{-}$mixes homogenously with the ${ }^{14} \mathrm{NO}_{3}{ }^{-}$ pool in the sediment (Eyre et al. 2002). Isotope fractionation is also assumed to be negligible (Middelburg et al. 1996). Linear production of ${ }^{14} \mathrm{~N}^{15} \mathrm{~N}$ and ${ }^{15} \mathrm{~N}^{15} \mathrm{~N}$ shows that Assumption 1 was satisfied. Based on the amount of ${ }^{15} \mathrm{NO}_{3}{ }^{-}$we added $(100 \mu \mathrm{M})$ and the measured rates, the tracer addition would only have changed the $D_{14}$ rates (Assumption 2) by about 10\% (Middelburg et al. 1996), and as such cannot explain our results. Assumption 3 also cannot explain our results because, if anammox were significant, it would result in an overestimation of denitrification (see Risgaard-Petersen et al. 2003). In addition, recent measurements in a similar sediment type, at a similar water depth, in a bay adjacent to the study area, showed very low relative rates of anammox $\left(0.1 \%\right.$ of total $\mathrm{N}_{2}$ production; R. Glud pers. comm.), which is also consistent with low relative rates of anammox in other sediments in shallow water (Dalsgaard et al. 2005). Given the apparent underestimation of denitrification by IP in association with the dominance of $D_{\mathrm{n}}$ during the present study, the most likely source of error is violation of Assumption 4.

Incomplete mixing of ${ }^{15} \mathrm{NO}_{3}{ }^{-}$with the endogenous source of ${ }^{14} \mathrm{NO}_{3}{ }^{-}$can cause underestimation of denitrification by IP in sediments where zones of nitrification and denitrification overlap, or, alternatively, where small-scale heterogeneity in sediment structure supports anaerobic micro-niches throughout the oxic nitrification zone (Van Luijn et al. 1996). Recent studies suggest that short-lived anoxic microniches can evolve in marine snow aggregates (R. Glud pers. comm.). The upper sediment layer at our study site that was removed by trawling consisted of a 'fluffy' layer of phytodetritus similar in appearance to marine snow aggregates. The simulation of overlapping nitrification and denitrification zones was achieved in the Middelburg et al. (1996) model by setting a $10 \mu \mathrm{M} \mathrm{O}_{2}$ threshold for denitrification inhibition, with a $50 \%$ overlap in zones causing a $12 \%$ underestimation of denitrification by IP; however, this is still insufficient to explain our results.

Visual inspection of the sediment surface during periods of highest discrepancy between methods confirmed the build-up of a heterogenous texture due to burrow structures, and the difference between methods increases with increasing polychaete biomass (Fig. 3). This coincided with a more mature polychaete population characterised by fewer, but larger deposit feeders and predators (authors' unpubl. data). The volume of potential denitrification sites (and hence areal rates of denitrification) would be significantly increased in these sediments due to the complex 3-dimensional redox zonation imparted by burrow structures, etc., within the oxic zone.

An increase in denitrification adjacent to burrow structures may be due to a combination of increased supply of nitrate (nitrification) and/or OC (Pelegri \& Blackburn 1996, De Roach et al. 2002). However, the diffusive permeability of the mucus linings of polychaete burrows can be as low as $10 \%$ of that in free solution (Kristensen 2000, Hannides et al. 2005). Hence, the supply of ${ }^{15} \mathrm{NO}_{3}{ }^{-}$via bio-irrigation to denitrification sites adjacent to burrow linings would be limited relative to endogenously supplied ${ }^{14} \mathrm{NO}_{3}{ }^{-}$from nitrifiers within the lining itself. For this to occur the ${ }^{15} \mathrm{NO}_{3}{ }^{-}$must diffuse through the burrowing lining, or part of the lining, at a lower rate than $\mathrm{O}_{2}$, which is required by the nitrifiers. This is feasible as $\mathrm{O}_{2}$ is a gas and ${ }^{15} \mathrm{NO}_{3}{ }^{-}$is an anion, the diffusion of which can be retarded by the complex biogenic components associated with macrofauna burrows (Hannide et al. 2005). The rate at which ${ }^{15} \mathrm{NO}_{3}{ }^{-}$and $\mathrm{O}_{2}$ pass through the burrow linings will also depend on the their consumption rates. If ${ }^{15} \mathrm{NO}_{3}{ }^{-}$diffusion is retarded it may lead to preferential use of ${ }^{14} \mathrm{NO}_{3}{ }^{-}$ by denitrifiers, causing an underestimation of denitrification by IP due to violation of Assumption 4. An underestimation of ${ }^{14} \mathrm{~N}^{15} \mathrm{~N}$ production by 5 to $40 \%$ (average $19 \%$ ) due to violation of Assumption 4 is sufficient to explain the differences between methods.

Strong support for this hypothesis is provided by both the positive relationship between the methods discrepancy and polychaete biomass $\left(\mathrm{r}^{2}=0.99\right.$; $\mathrm{p}<$ 0.001; Fig. 3), and the virtual removal of the methods discrepancy by trawling, which destroyed the heterogenous texture imparted by burrow structures (Fig. 5). Due to the disturbance created by resuspension of the surface layer, post-trawl sediments exhibited a more 2-dimensional redox profile. The $\mathrm{N}_{2}$ : $\mathrm{Ar}$ rates were still slightly higher than the IP rates, most likely due the effects of residual burrow structures below the depth of trawl damage.

\section{${ }^{15} \mathrm{NO}_{3}{ }^{-}$additions}

A concentration series, in which different amounts of ${ }^{15} \mathrm{NO}_{3}{ }^{-}$are added to the overlying water during an IP experiment, is a standard test to determine if there is homogenous mixing of ${ }^{15} \mathrm{NO}_{3}{ }^{-}$with the endogenous source of ${ }^{14} \mathrm{NO}_{3}{ }^{-}$(Nielsen 1992, Eyre et al. 2002). Unfortunately, we did not do a concentration series experiment. We chose instead to minimise the effect of incomplete mixing of ${ }^{15} \mathrm{NO}_{3}{ }^{-}$with ${ }^{14} \mathrm{NO}_{3}{ }^{-}$, by using very high concentrations of ${ }^{15} \mathrm{NO}_{3}{ }^{-}$in our experiments (100 $\mu \mathrm{M}$ against a background of $<5 \mu \mathrm{M}$ ); a concentration that would typically be considered the upper limit of a concentration series experiment (see Eyre et al. 2002). 
The final ${ }^{15} \mathrm{NO}_{3}{ }^{-}$concentration was also well above the recommended $20 \%$ of the average site oxygen concentration (mean $\mathrm{O}_{2}$ saturation $=98 \%$ ) and 30 at. $\%$ in the $\mathrm{NO}_{3}$ pool (Dalsgaard et al. 2000). At higher concentrations of ${ }^{15} \mathrm{NO}_{3}{ }^{-}$more of the denitrified ${ }^{14} \mathrm{NO}_{3}{ }^{-}$will be measured as ${ }^{14} \mathrm{~N}^{15} \mathrm{~N}$, thereby lowering the underestimation of $D_{14}$ (Nielsen 1992, Eyre et al. 2002). It is possible, however, that the problem of incomplete mixing of ${ }^{15} \mathrm{NO}_{3}{ }^{-}$with ${ }^{14} \mathrm{NO}_{3}{ }^{-}$in the sediments of oligotrophic systems may be overcome if a ${ }^{15} \mathrm{NO}_{3}{ }^{-}$concentration $>100 \mu \mathrm{M}$ is used in the IP experiments. As such, our findings only demonstrate a discrepancy between methods when an addition of ${ }^{15} \mathrm{NO}_{3}{ }^{-}$up to $100 \mu \mathrm{M}$ is used. Further work is required to determine if this discrepancy remains when even larger amounts of ${ }^{15} \mathrm{NO}_{3}{ }^{-}$ are added during the IP experiments. Although such large additions of ${ }^{15} \mathrm{NO}_{3}{ }^{-}$to sediments from an oligotrophic system may result in denitrification rates no longer depending linearly on the concentration of nitrate, due to a limited supply of electron donors, Michaelis-Menten-type saturation and increased nitrate penetration depth (Steingruber et al. 2001).

\section{Pre-incubation times}

The critical question arises as to whether longer preincubation times would be sufficient to overcome the bias in ${ }^{14} \mathrm{NO}_{3}{ }^{-}:{ }^{15} \mathrm{NO}_{3}{ }^{-}$mixing associated with bioturbation structures because the tracer could mix down through the sediment (i.e. not transported down the burrows). In sandy sediments it takes $24 \mathrm{~h}$ for steadystate conditions to be reached after addition of the ${ }^{15} \mathrm{NO}_{3}{ }^{-}$tracer (Cook et al. 2006). Our study allowed approximately $3 \mathrm{~h}$ for uniform mixing to occur, and incubations were run over the following $24 \mathrm{~h}$ (Fig. 1). While these data are subject to noise from spatial variation (i.e. each time point is an individual core), there was no indication of an increase in $D_{14}$ rates with time during any run, as would be expected if homogenous mixing of ${ }^{14} \mathrm{NO}_{3}{ }^{-}:{ }^{15} \mathrm{NO}_{3}{ }^{-}$was only approached as the incubation progressed. Further, runs tests (Motulsky \& Christopoulos 2003) showed that none of the ${ }^{14} \mathrm{~N}^{15} \mathrm{~N}$ and ${ }^{15} \mathrm{~N}^{15} \mathrm{~N}$ time series carried out during this study were significantly non-linear $(p<0.01)$. This suggests that the IP technique may consistently underestimate denitrification in bioturbated sediments, regardless of pre-incubation times. It is unclear whether longer preincubation times (>24 h) would overcome the problem.

Acknowledgements. This work was supported by an ARC Linkage Grant (LP0212075) awarded to B.D.E., A.J.P.F. and John Kirkwood, and an ARC Discovery Grant (DP0342956) awarded to B.D.E. The ARC Linkage Project was in partnership with the Moreton Bay Waterways and Catchments Part- nership, the Queensland Department of Primary Industries and the Queensland Environmental Protection Authority who provided logistical support. We thank our divers and boat crew Simon Hartley, Danny Bucher and Max Egan, our field assistants Paul Kelly, Damien Maher, Jodie Walker, Jamie Potts and Geoff Coade, and our analyst Iain Alexander. The helpful comments of Søren Rysgaard, Ronnie Glud, and several reviewers improved earlier drafts of the manuscripts.

\section{LITERATURE CITED}

Banta GT, Giblin AE, Tucker J, Hobbie JE (1994) Comparison of two indirect methods of estimating denitrification rates for Buzzards Bay, Massachusetts. In: Dyer KR, Orth RJ (eds) Changes in fluxes in estuaries: implications from science to management. Olsen \& Olsen, Fredensborg, p 301-338

Berelson W, Heggie D, Longmore A, Kilgore T, Nicholson G, Skyring G (1998) Benthic nutrient recycling in Port Phillip Bay, Australia. Estuar Coast Shelf Sci 46:917-934

Christensen PB, Nielsen LP, Sørensen J, Revsbech NP (1990) Denitrification in nitrate-rich streams: diurnal and seasonal variation related to benthic oxygen metabolism. Limnol Oceanogr 35:640-651

Cook PLM, Wenzhofer F, Rysgaard S, Galaktionov OS and others (2006) Quantification of denitrification in permeable sediments; insights from a 2 dimensional simulation analysis and experimental data. Limnol Oceanogr Methods 4:294-307

Dalsgaard T, Nielsen LP, Brotas V, Viaroli P and others (2000) Protocol handbook for NICE - nitrogen cycling in estuaries. National Environmental Research Institute, Silkeborg

Dalsgaard T, Thamdrup B, Canfield DE (2005) Anaerobic ammonium oxidation (anammox) in the marine environment. Res Microbiol 156:457-464

De Roach RJ, Rate AW, Knott B, Davies PM (2002) Denitrification activity in sediment surrounding polychaete (Ceratonereis aequisetis) burrows. Mar Freshw Res 53:35-41

Eyre BD, Ferguson AJP (2002) Comparison of carbon production and decomposition, benthic nutrient fluxes and denitrification in seagrass, phytoplankton, benthic microalgaeand macroalgae-dominated warm-temperate Australian lagoons. Mar Ecol Prog Ser 229:43-59

Eyre BD, Ferguson AJP (2005) Benthic metabolism and nitrogen cycling in a sub-tropical east Australian estuary (Brunswick) - temporal variability and controlling factors. Limnol Oceanogr 50:81-96

Eyre BD, Rysgaard S, Dalsgaard T, Christensen PB (2002) Comparison of isotope pairing and $\mathrm{N}_{2} / \mathrm{Ar}$ methods for measuring sediment denitrification rates - assumptions, modifications and implications. Estuaries 25:1077-1087

Ferguson AJP, Eyre BD, Gay J (2003) Organic matter and benthic metabolism in euphotic sediments along shallow sub-tropical estuaries, northern NSW, Australia. Aquat Microb Ecol 33:137-154

Hannides AK, Dunn SM, Aller RC (2005) Diffusion of organic and inorganic solutes through macrofaunal mucus secretions and tube linings in marine sediments. J Mar Res 63: 957-981

Kana TM, Darkangelo C, Hunt MD, Oldam JB, Bennett GE, Cornwell JC (1994) Membrane inlet mass spectrometer for rapid high-precision determination of $\mathrm{N}_{2}, \mathrm{O}_{2}$, and $\mathrm{Ar}$ in environmental samples. Analyt Chem 66:4166-4170

Kana TM, Sullivan MB, Cornwell JC, Groszkowski KM (1998) Denitrification in estuarine sediments determined by membrane inlet mass spectrometry. Limnol Oceanogr 43: $334-339$ 
Kristensen E (2000) Organic matter diagenesis at the oxic/anoxic interface in coastal marine sediments, with emphasis on the role of burrowing organisms. Hydrobiologia 426:1-24

Middelburg JL, Soetaert K, Herman PMJ (1996) Evaluation of the nitrogen isotope pairing method for measuring benthic denitrification: a simulation analysis. Limnol Oceanogr 41: 1839-1844

Motulsky HJ, Christopoulos A (2003) Fitting models to biological data using linear and nonlinear regression. A practical guide to curve fitting. GraphPad Software, San Diego, CA

Nielsen LPM (1992) Denitrification in sediment determined from nitrogen isotope pairing. FEMS Microbiol Ecol 86: $357-362$

Nixon S (1981) Remineralization and nutrient cycling in coastal marine ecosystems. In: Neilson BJ, Cronin LE (eds) Estuaries and nutrients. Humana, Totowa, NJ, p 111-138

Nixon SW (1987) Chesapeake Bay nutrient budgets - a reassessment. Biogeochemistry 4:77-90

Pelegri SP, Blackburn TH (1996) Nitrogen cycling in lake sediments bioturbated by Chironomus plumosus larvae, under different degrees of oxygenation. Hydrobiologia 325:231-238

Risgaard-Petersen N, Rysgaard S, Nielsen LP, Revsbech NP (1994) Diurnal variation of denitrification and nitrification in sediments colonised by benthic microphytes. Limnol Oceanogr 39:573-579

Risgaard-Petersen N, Nielsen LP, Blackburn TH (1998) Simultaneous measurement of benthic denitrification with the isotope pairing technique and the $\mathrm{N}_{2}$ flux method in a continuous flow-through system. Water Res $32: 3371-3377$

Editorial responsibility: Victor de Jonge (Contributing Editor), Haren, The Netherlands
Risgaard-Petersen N, Nielsen LP, Rysgaard S, Dalsgaard T, Meyer RL (2003) Application of the isotope pairing technique in sediments where anammox and denitrification coexist. Limnol Oceanogr Methods 1:63-73

Rysgaard S, Risgaard-Petersen N, Sloth NP, Jensen K, Nielsen LP (1994) Oxygen regulation of nitrification and denitrification in sediments. Limnol Oceanogr 39: 1643-1652

Rysgaard S, Risgaard-Petersen N, Sloth NP (1996) Nitrification, denitrification, and nitrate ammonification in sediments of two coastal lagoons in southern France. Hydrobiologia 329:133-141

Seitzinger SP (1987) Nitrogen biogeochemistry in an unpolluted estuary: the importance of benthic denitrification. Mar Ecol Prog Ser 41:177-186

Seitzinger SP (1988) Denitrification in freshwater and coastal marine ecosystems: ecological and geochemical significance. Limnol Oceanogr 33:702-724

Sørensen J (1978) Denitrification rates in a marine sediments as measured by the acetylene inhibition technique. Appl Environ Microbiol 36:139-143

Steingruber SM, Friedrich J, Gachter R, Wehrli B (2001) Measurement of denitrification in sediments with the ${ }^{15} \mathrm{~N}$ isotope pairing technique. Appl Environ Microbiol 67: $3771-3778$

Sundback K, Miles A (2000) Balance between denitrification and microalgal incorporation of nitrogen in microtidal sediments, NE Kattegat. Aquat Microb Ecol 22:291-300

Van Luijn F, Boers PCM, Lijklema L (1996) Comparison of denitrification rates in lake sediments obtained by the $\mathrm{N}_{2}$ flux method, the ${ }^{15} \mathrm{~N}$ isotope pairing technique and the mass balance approach. Water Res 30:893-900

Submitted: January 25, 2007; Accepted: July 10, 2007

Proofs received from author(s): November 13, 2007 